\title{
Performance of 4-Subsituted Pyridine Based Additive and Cobalt Redox in PEG-HEC Polymer Electrolytes with DTTCY Sensitizer on Dye Sensitized Solar Cells
}

\author{
Santhosh Kamaraj ${ }^{a}$, Ganesan Shanmugam*, Ahalya Gunasekeran ${ }^{\mathrm{b}}$, Balamurugan Selvaraj ${ }^{\mathrm{a}}$, \\ Eswaramoorthi Thirugnanasambandama, Mohanraj Kandhasamy ${ }^{\mathrm{a}}$, Anandan Sambandamb. \\ a Advanced Organic Chemistry Laboratory, Department of Chemistry, SRM Institute of Science and \\ Technology, Kattankulathur, 603203, Tamil Nadu, India. \\ b Nanomaterials and Solar Energy Conversion Lab, Department of Chemistry, National Institute of Technology, \\ Tiruchirappalli 620015, Tamil Nadu, India
}

\section{$\underline{\text { Supporting Information }}$}

Content

page

$>\left({ }^{1} \mathrm{H}\right.$ NMR $\&{ }^{13} \mathrm{C}$ NMR $)$ of all new additive compounds

S1

$>$ CHNS analysis of heterocyclic aromatic pyridine additive

S7

$>$ Electrochemical properties of $\mathrm{Co}^{2+/ 3+}[$ bnbip] redox couple

S7

$>$ Photovoltaic performance

S8

$>$ Stability test of Device

S9

$>$ Integrated Current density of Device

* Corresponding author.

Tel: +91-44-2741 7872

Fax: +91-44-2745 2343

Email: shreesakthi77@gmail.com,ganesan.s2@srmist.edu.in. 

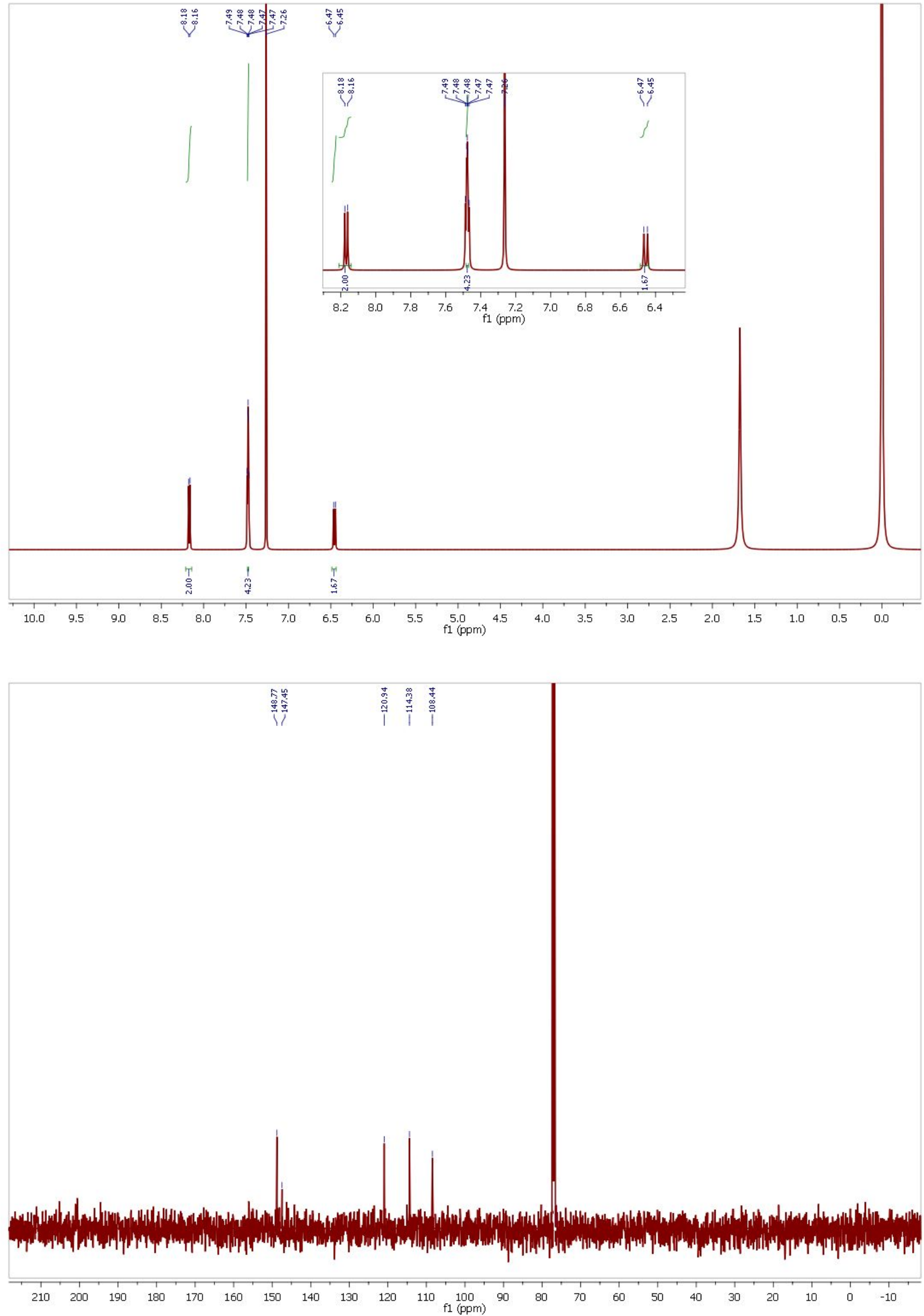

Figure S1 : ${ }^{1} \mathrm{H}$ NMR \& ${ }^{13} \mathrm{C}$ NMR spectrum of compound PP 

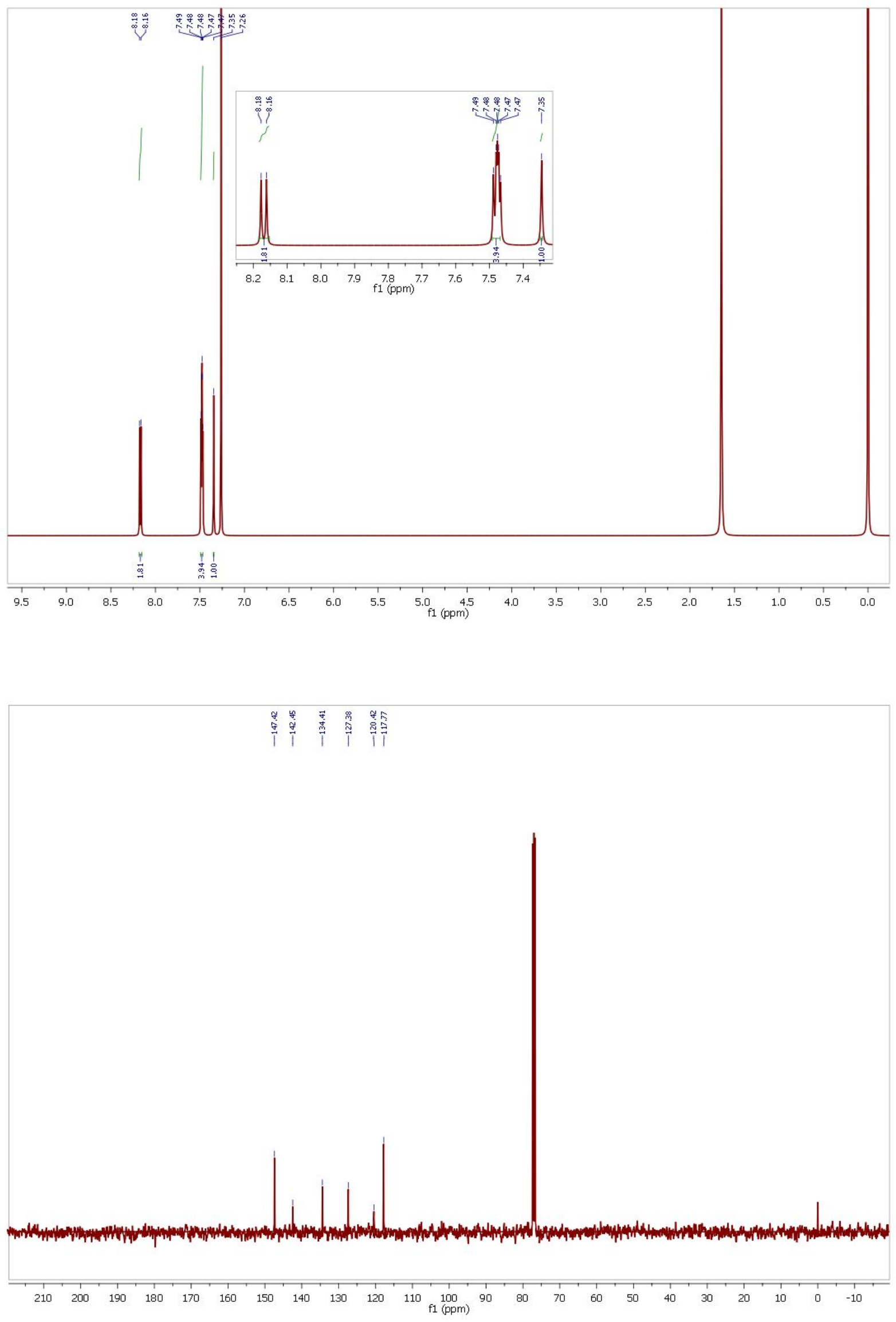

Figure S2 : ${ }^{1} \mathrm{H}$ NMR \& ${ }^{13} \mathrm{C}$ NMR spectrum of compound PIZ 

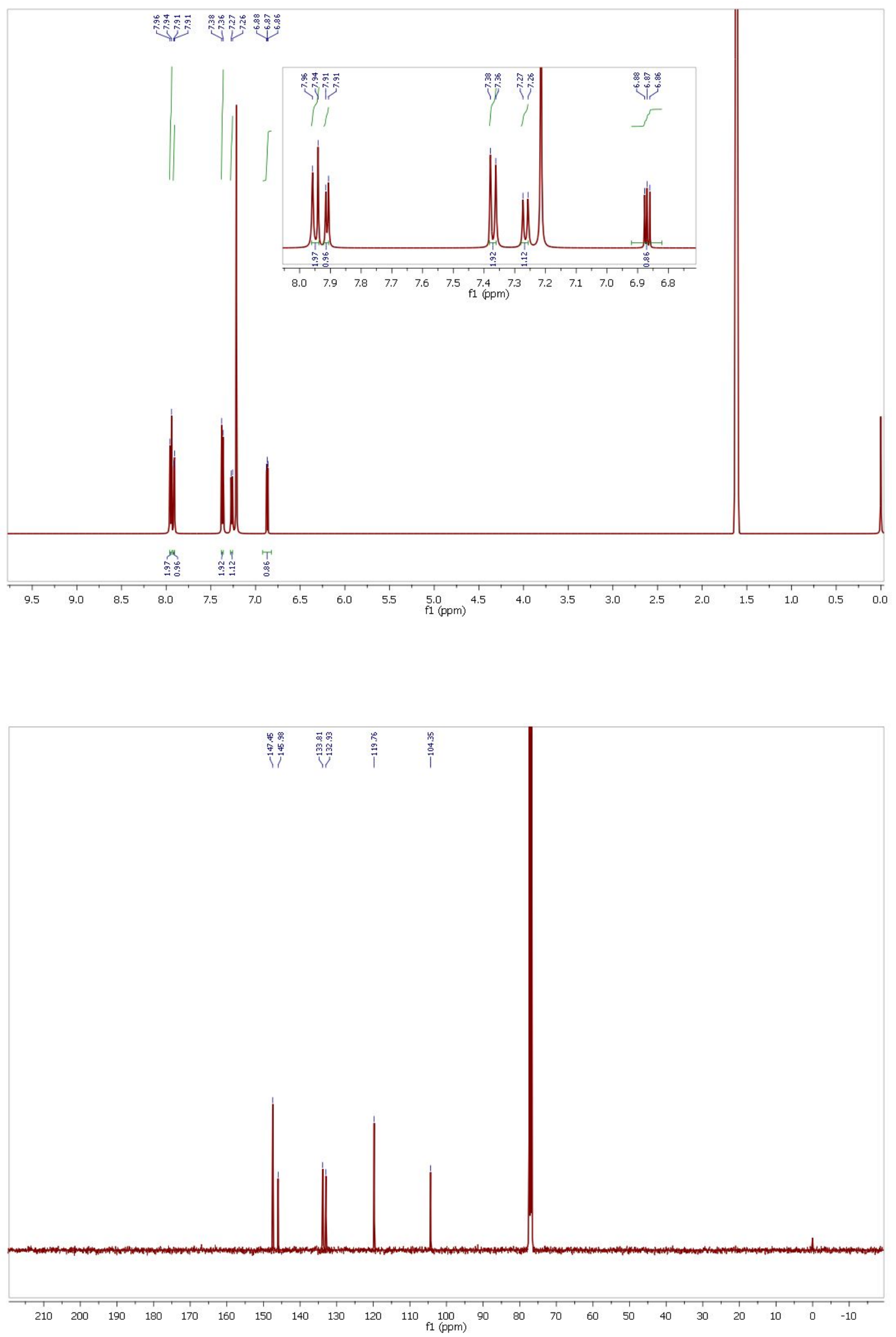

Figure S3 : ${ }^{1} \mathrm{H}$ NMR \& ${ }^{13} \mathrm{C}$ NMR spectrum of compound PPZ 

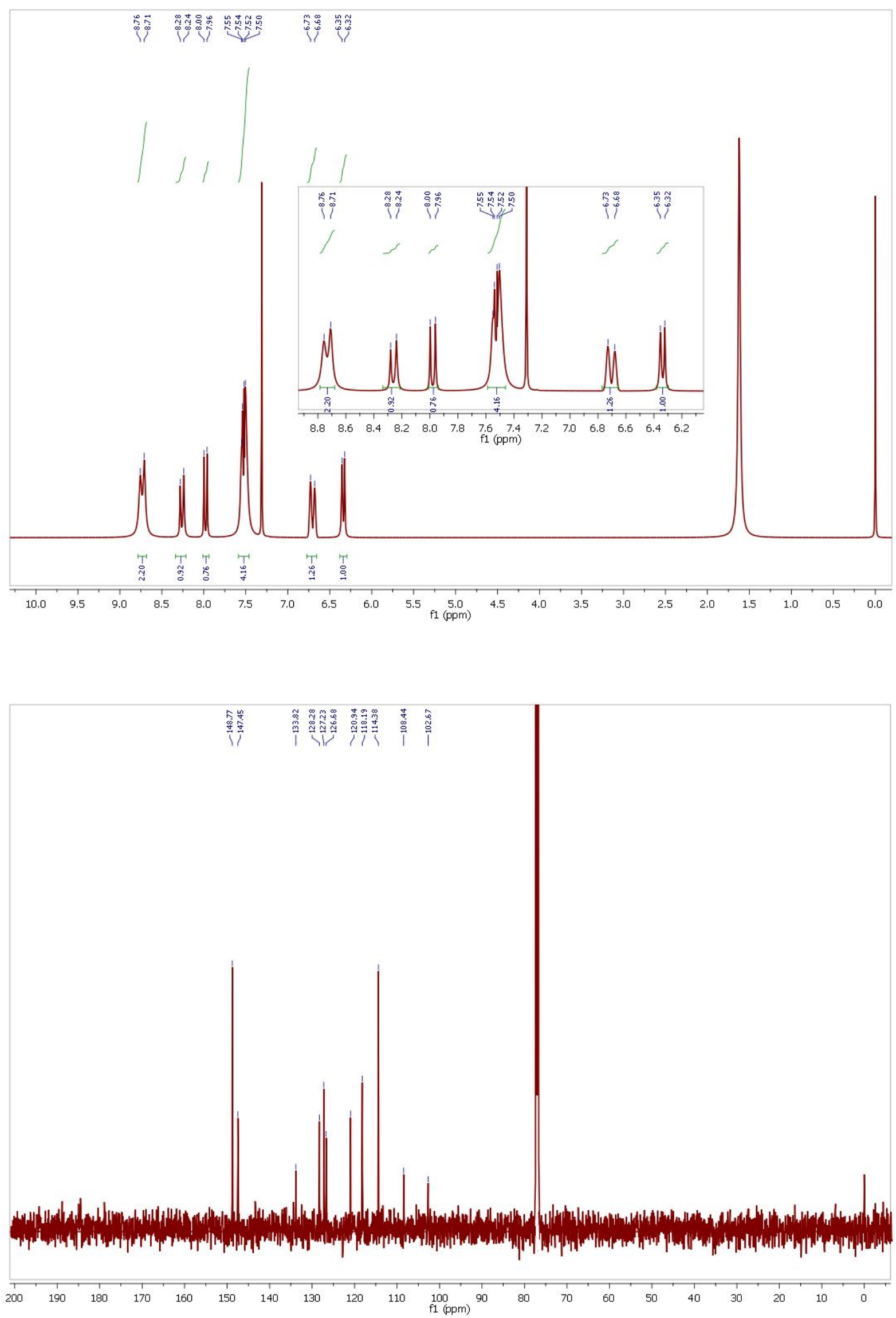

Figure S4 : ${ }^{1} \mathrm{H}$ NMR \& ${ }^{13} \mathrm{C}$ NMR spectrum of compound PIN 

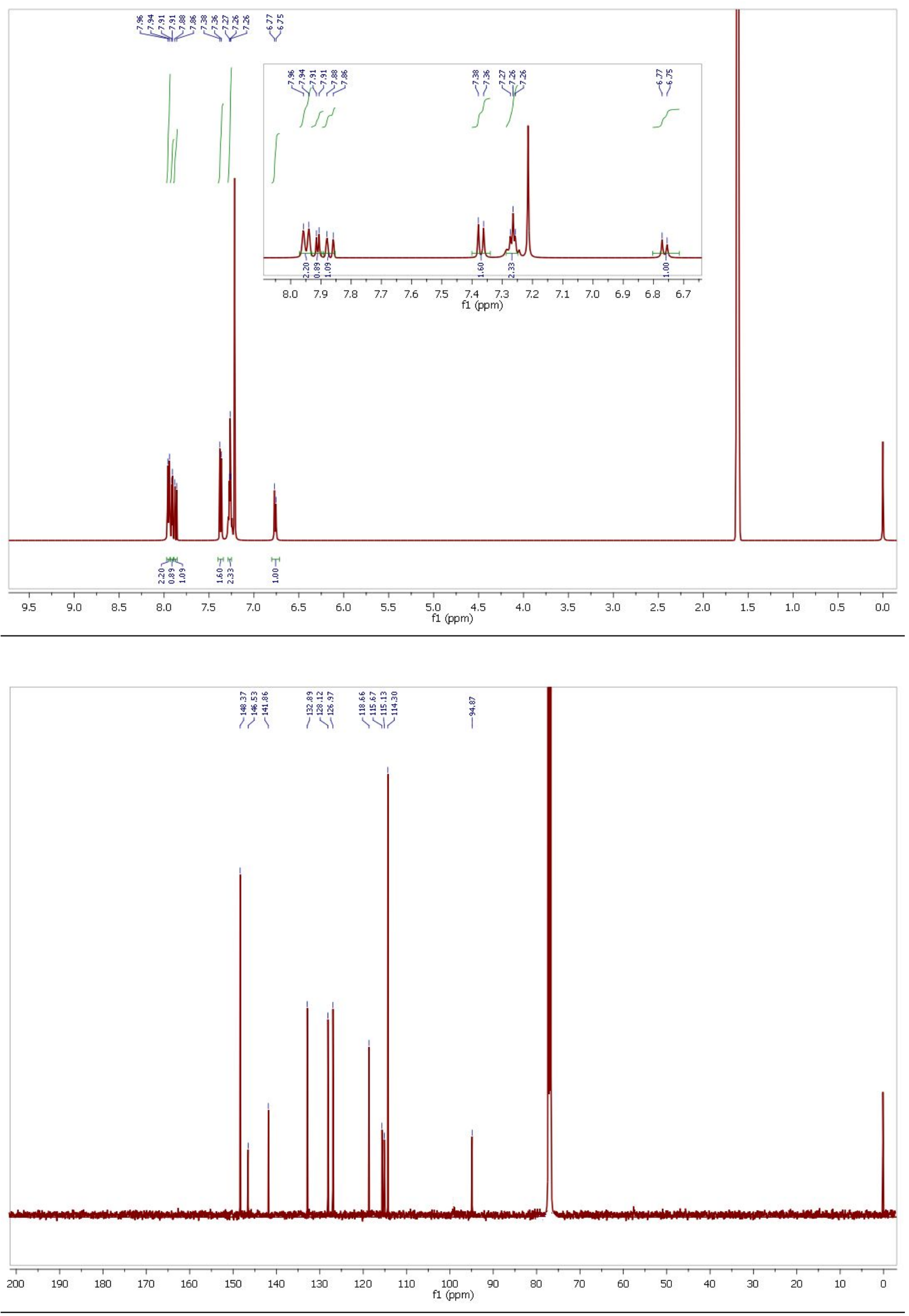

Figure S5 : ${ }^{1} \mathrm{H}$ NMR \& ${ }^{13} \mathrm{C}$ NMR spectrum of compound PAZ 
Table S1 CHN analysis of heterocyclic aromatic pyridine additive molecules

\begin{tabular}{ccccc}
\hline & & \multicolumn{3}{c}{ Percentage composition (\%) } \\
& & Carbon & Hydrogen & Nitrogen \\
\hline $\mathrm{PP}$ & Experimental & 74.98 & 5.59 & 19.43 \\
$\mathrm{C}_{8} \mathrm{H}_{8} \mathrm{~N}_{2}$ & Computed & 74.29 & 5.82 & 19.89 \\
$\mathrm{PIZ}$ & Experimental & 66.19 & 4.86 & 28.95 \\
$\mathrm{C}_{8} \mathrm{H}_{7} \mathrm{~N}_{3}$ & Computed & 66.02 & 4.48 & 29.50 \\
$\mathrm{PPZ}$ & Experimental & 66.19 & 4.86 & 28.95 \\
$\mathrm{C}_{8} \mathrm{H}_{7} \mathrm{~N}_{3}$ & Computed & 66.40 & 4.96 & 28.64 \\
$\mathrm{PIN}$ & Experimental & 80.39 & 5.19 & 14.42 \\
$\mathrm{C}_{13} \mathrm{H}_{10} \mathrm{~N}_{2}$ & Computed & 80.55 & 5.44 & 14.01 \\
$\mathrm{PAZ}_{\mathrm{C}}$ & Experimental & 73.83 & 4.65 & 21.52 \\
$\mathrm{C}_{12} \mathrm{H}_{9} \mathrm{~N}_{3}$ & Computed & 74.51 & 4.22 & 21.27
\end{tabular}

CHN analysis was carried out using CHN elemental analyser model Vario EL III. The percentage composition of Carbon, Hydrogen and Nitrogen obtained in the sample are tabulated below

\section{Cyclic Voltammogram of compounds}

The electrochemical behaviour of Co[bnbip $]^{2+/ 3+}$ redox couple were determined using cyclic voltammograms. From three electrodes system consist of $\mathrm{Pt}$ as working electrode, $\mathrm{Pt}$ wire as counter electrode and $\mathrm{Ag} / \mathrm{AgCl}$ as reference electrode. The $0.1 \mathrm{M}$ of supporting electrolyte and $3.0 \mathrm{mM}$ solution of redox complex in acetonitrile solution. The anodic and cathodic peaks were observed due to the redox reaction occur between the $\mathrm{Co} 2+$ ions to $\mathrm{Co}^{3+}$ ions.

$$
E_{1 / 2 \text { (ferrocene) }}=\frac{E^{o x}+E^{r e d}}{2}
$$

The $E_{\text {red }}$ and $E_{\text {oxd }}$ peak occurs at $0.55 \mathrm{~V}$ and $0.48 \mathrm{~V}$ respectively. The $\mathrm{E}_{1 / 2}$ value of the redox couple is $0.515 \mathrm{~V}$ vs NHE. These values are used to determine the Quasi Fermi level of the system. 


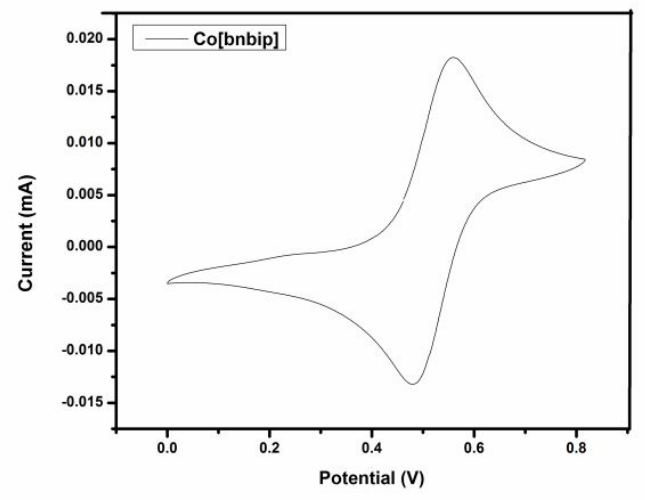

Figure S6 Cyclic voltammogram of $\mathrm{Co}^{2+/ 3+}$ [bnbip] $\left(3.0 \times \mathbf{~ 1 0}^{-3} \mathrm{M}\right)$ in acetonitrile solution containing tetrabutylammonium perchlorate $(0.1 \mathrm{M})$ as supporting electrolyte with scan rate of $50 \mathrm{mV} \mathrm{s} \mathbf{s}^{-1}$

Photovoltaic performance

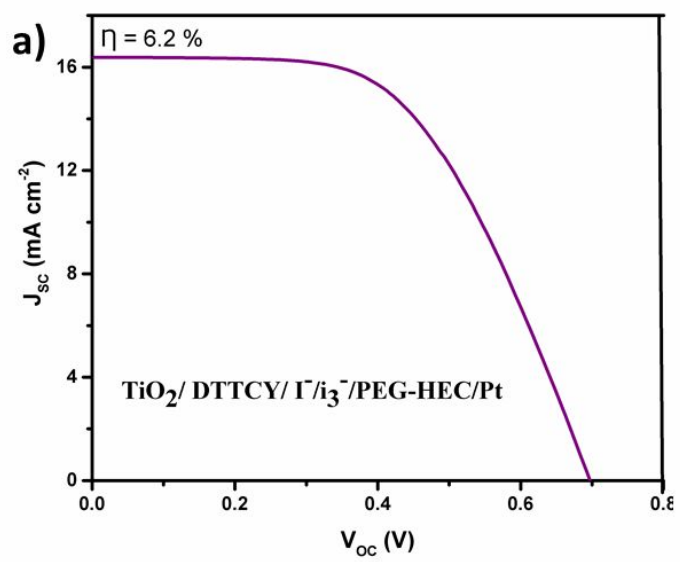

b)

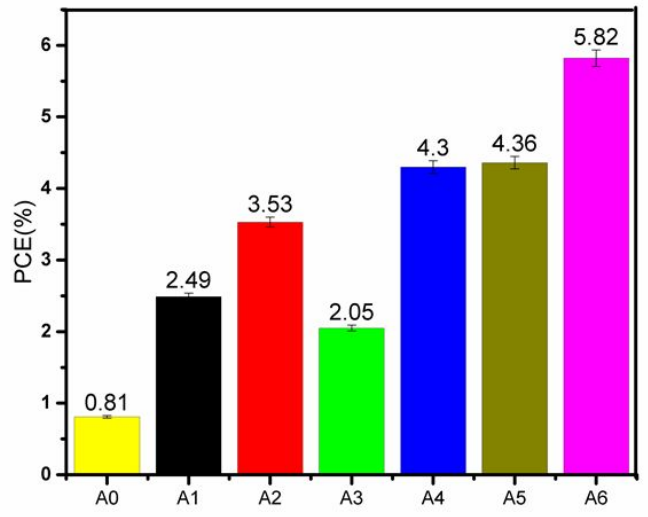

Figure $\mathrm{S} 7$ a) Photovoltaic performance of $\mathrm{TiO}_{2} / \mathrm{DTTCY}$ dye/I-// 3 -/PEG-HEC/TBP additive/Pt. b) the reproducibility of Power Conversion efficiency with deviation obtained from 3 set of device 

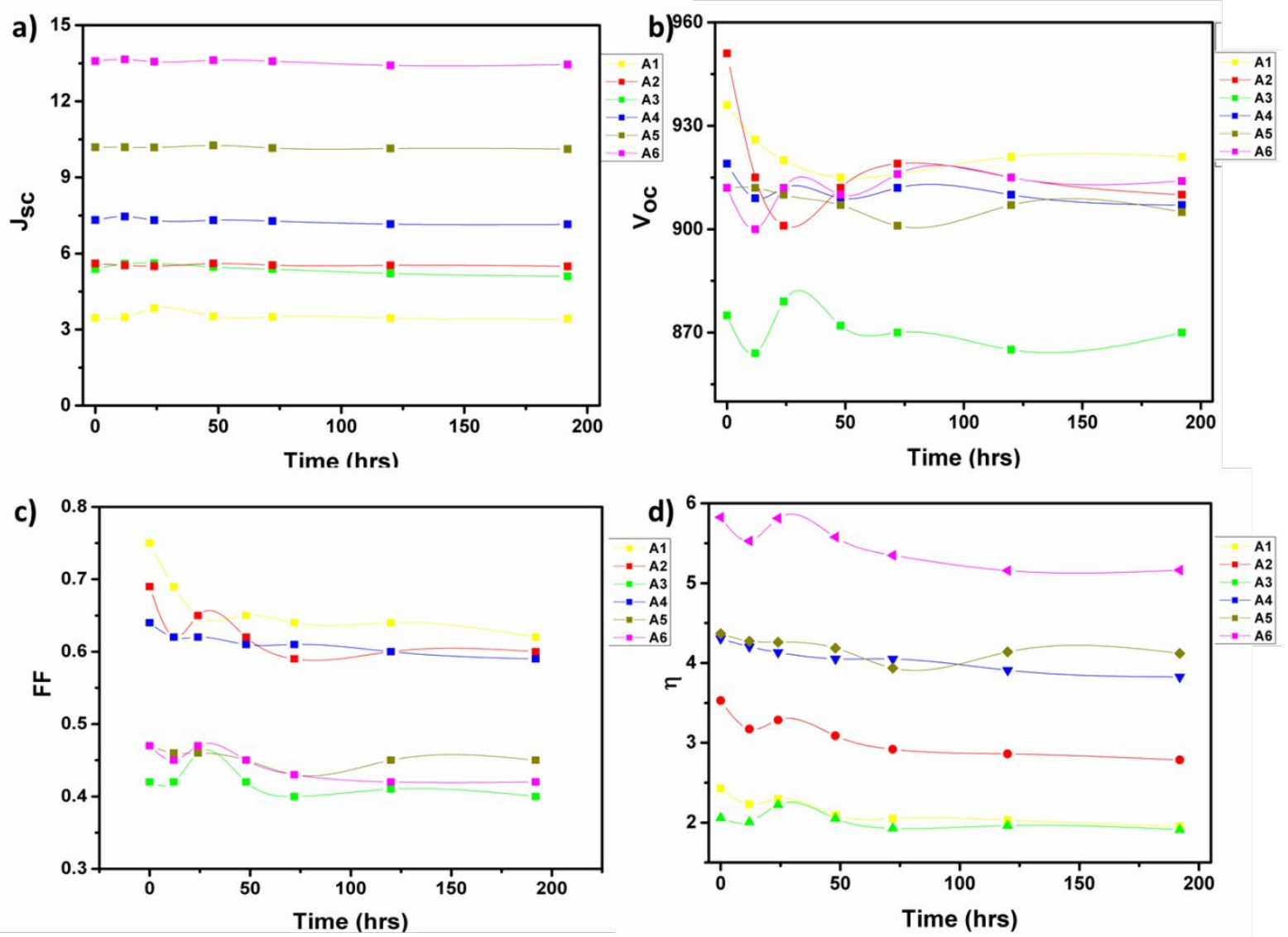

Figure S8 Photo-stability test of $\mathrm{TiO}_{2} / \mathrm{DTTCY}$ dye/ $\mathrm{Co}^{2+/ 3+}$ [bnbip] /PEG-HEC/ with additive/Pt for $0,12,24,48,72,120$ and 196 hours a) photo-current density, b) photovoltage, c) Fill factor, d) Power Conversion efficiency

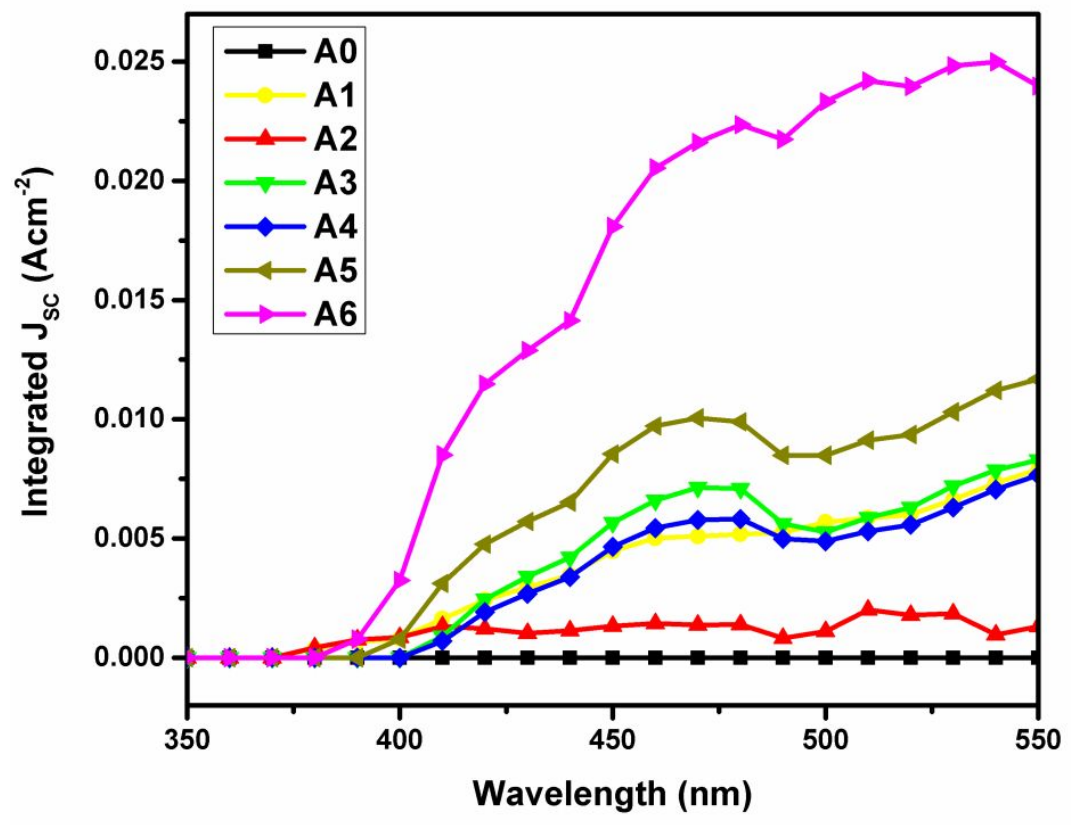

Figure S9 Integrated current density of $\mathrm{TiO}_{2} / \mathrm{DTTCY}$ dye/ $\mathrm{Co}^{2+/ 3+}[\mathrm{bnbip}] / \mathrm{PEG}-\mathrm{HEC} /$ with additive/Pt 